Revista Perspectivas Online: Humanas \& Sociais Aplicadas

Novembro/2020, v.10, n.29, p.34-45 ISSN: 2236-8876 (Online) DOI: $10.25242 / 8876102920201956$

\title{
EXPANSÃO DEMOGRÁFICA E ABASTECIMENTO DE ÁGUA NO SISTEMA INTEGRADO DE FEIRA DE SANTANA/BA
}

\author{
Gleice da Silva Aguiar', Telma C. S. Teixeira ${ }^{1,2 *}$, Frank Pavan $^{3}$ \& Karine Veiga dos \\ Santos $^{1}$
}

\section{RESUMO}

AGUIAR, G. S.; TEIXEIRA, T. C. S. PAVAN, F; SANTOS, K. V. Expansão Demográfica e Abastecimento de Água no Sistema Integrado de Feira de Santana/BA. Perspectivas Online: Humanas \& Sociais Aplicadas, v.10, n.29, p.34 - 452020.

Sistemas de abastecimento de água são estruturas que integram as fontes de água, onde ocorre a captação, à rede de distribuição que serve a população. Nesse processo, vazamentos comprometem a disponibilidade do recurso hídrico e as receitas dos prestadores, afetando a oferta de água. Paralelamente, a demanda é pressionada pela natural expansão demográfica. $\mathrm{O}$ presente trabalho analisa esses elementos de oferta e demanda no Sistema Integrado de Abastecimento de Água de Feira de Santana, localizado no semiárido baiano. Através de hipóteses de redução nas perdas reais, são simulados cenários de demanda que consideram a projeção populacional estimada pelos órgãos estaduais de estatística para os anos de 2020, 2025 e 2030, supondo aumento e manutenção nos padrões de consumo. Os resultados evidenciam a já presente insuficiência para atendimento à população, cuja média de consumo é de $86,80 \mathrm{l} / \mathrm{dia}$. Investimentos que reduzam as perdas reais se mostram eficientes apenas quando mantido $o$ atual padrão de demanda, abaixo dos 110 1/dia indicado pela Organização Mundial de Saúde.

Palavras-chave: Demanda de água; crescimento populacional; perdas de água; semiárido. 


\title{
DEMOGRAPHIC EXPANSION AND WATER SUPPLY IN THE INTEGRATED WATER SYSTEM OF FEIRA DE SANTANA / BA
}

\begin{abstract}
Water supply systems are structures that integrate the water sources, where the withdrawn takes place, to the distribution network that serves the population. In this process, leakages compromise the availability of water resources and the revenues of providers, affecting the supply of water. At the same time, demand is pressured by the natural demographic expansion. The present work analyzes these elements of supply and demand in the Integrated Water Supply System of Feira de Santana, located in the semiarid

region of Bahia. Through hypotheses of reduction in real losses, demand scenarios are simulated considering the population projection estimated by the state agency of statistic for the years 2020, 2025 and 2030, assuming an increase and maintenance in consumption patterns. The results show the present insufficiency to serve the population, whose average consumption is $86.801 /$ day. Investments that reduce real losses are only effective when the demand pattern is maintained below the $110 \mathrm{l} /$ day indicated by Health Mundial Organization.
\end{abstract}

Keywords: Water demand; population growth; water loss; semiarid region.

${ }^{1}$ Grupo de Estudos em Recursos Hídricos e Sustentabilidade (RHIOS). Av. Transnordestina S/N, Módulo 5 - Sala MT56, Campus Universitário, Novo Horizonte, Feira de Santana, BA, CEP: 44036-900, Brasil;

${ }^{2}$ Universidade Estadual de Feira de Santana - Departamento de Ciências Sociais Aplicadas. Av. Transnordestina S/N, Campus Universitário, Novo Horizonte, Feira de Santana, BA, CEP: 44036-900, Brasil.

${ }^{3}$ Institutos Superiores de Ensino do CENSA - ISECENSA - Rua Salvador Correa, 139, Centro, Campos dos Goytacazes, RJ, CEP: 28035-310, Brasil.

(*) e-mail: telma@uefs.br;

Data de recebimento: 03/02/2020. Aceito para publicação: 21/07/2020. Data da publicação: 27/11/2020

Persp. Online: hum \& sociais aplicada., Campos dos Goytacazes, 29 (10)34-45- 2020 seer.perspectivasonline.com.br 


\section{INTRODUÇÃO}

O Saneamento básico consiste em um conjunto de ações voltadas a modificações do espaço físico natural do meio ambiente de forma a criar condições primárias para garantia de uma melhor qualidade de vida da população. Como resultado de tais ações, entre diversos benefícios associados ao aumento de bem estar, torna-se possível prevenir ou reduzir condições que levam a proliferação de enfermidades propiciando um aumento na produtividade individual do adulto e desenvolvimento cognitivo infantil (FUNASA, 2010).

No Brasil o saneamento é assegurado pela Constituição Federal e normalizado pela Lei $n^{\circ}$ 11.445/2007 (BRASIL, 2005) - Plano Nacional de Saneamento (PLANSAB), definido como um amplo conjunto de serviços e infraestruturas ligados ao abastecimento de água, esgotamento sanitário, resíduos sólidos e águas pluviais.

Centrando a atenção nos serviços de abastecimento de água, condição sine qua non para a vida humana, verifica-se que muitos municípios no país não têm atendimento adequado. Com uma amostra de 5.147 municípios, representando mais de $92 \%$ do total nacional, o Sistema Nacional de Informações sobre Saneamento (SNIS) informou que em 2018 mais de 34 milhões de pessoas encontravam-se excluídas das redes de abastecimento de água (BRASIL/SNS, 2019). Para os demais atendidos, paralisações nos serviços, interrupções sistemáticas e descontinuidade no fluxo de fornecimento obrigam a manutenção de reservatórios nas residências para armazenamento. Como resultado, muitas dessas intermitências só são efetivamente observadas quando ocorre o esgotamento da reserva existente, mascarando informações sobre a qualidade dos serviços prestados.

Concomitante a exclusão e intermitência no fornecimento, o setor ainda precisa lidar com desafios como as perdas de água decorrentes de não faturamento (perdas aparentes) e vazamentos (perdas reais) na rede de distribuição que no ano de 2018 alcançou média nacional de 38,5\% (BRASIL/SNS, 2019). Como resultado, além de não atendimento a demanda existente, o desperdício de água compromete infraestruturas de pavimentação, onera custos operacionais das empresas de abastecimento, acarreta danos à saúde da população pelos riscos de contaminação e reduz a receita dos prestadores, sendo também a população responsável por arcar com o ônus financeiro derivado dos custos excedentes (LAMBERT; HIRNER, 2000).

Ainda no âmbito da oferta, conforme apontado por Pavan de Souza et al (2016), o crescimento populacional é uma das variáveis que pressiona os recursos hídricos. Assim, corroborando a necessidade de planejamento e políticas de gestão mais sustentáveis, faz-se necessário avaliar as pressões da demanda por água diante de projeções demográficas, garantindo instrumentos norteadores acerca da disponibilidade hídrica para abastecimento. Nesse sentido, opções sustentáveis perpassam por uma visão conceitual mais ampla do termo (MACHADO; VALE, 2015), observando não apenas os aspectos qualitativos das moradias, abordado por Siqueira e Araújo (2014), mas também na adequabilidade das estruturas para a oferta de serviços fundamentais para a população, como o abastecimento de água, realizado por sistemas específicos para este fim.

No contexto de desenvolvimento de infraestruturas, ao longo do processo de urbanização, a indispensabilidade da água para a sobrevivência humana justificou o desenvolvimento de tecnologias de transferência do recurso em prol de propiciar o assentamento populacional além do desenvolvimento de atividades econômicas como agricultura e criação animal (BARRAQUÉ, 2010). Os sistemas de abastecimento de água

Persp. Online: hum \& sociais aplicada., Campos dos Goytacazes, 29 (10)34-45- 2020 seer.perspectivasonline.com.br 
através dos quais são feitas as transferências de recursos são elementos infraestruturais essenciais à população. Através dos mesmos faz-se possível o acesso a fontes distantes dos centros urbanos de consumo, ao tempo em que são garantidos os padrões de potabilidade a água disponibilizada. Deste modo, esses sistemas integram os pontos de captação do recurso hídrico em sua forma bruta (não tratada) à rede de distribuição (Figura 1).

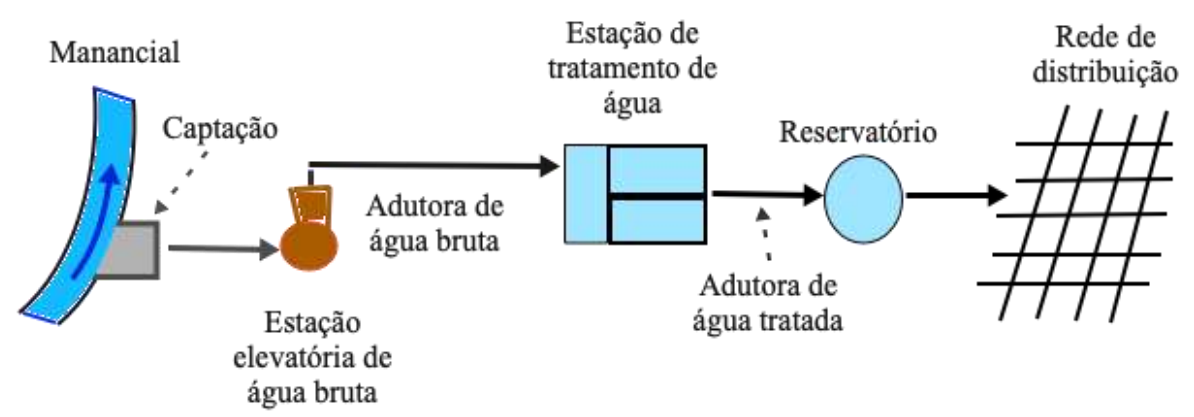

Figura 1: Modelo de sistema de abastecimento de água.

O Sistema Integrado de Abastecimento de Água de Feira de Santana (SIAA-FSA) capta o recurso hídrico na Barragem Pedra do Cavalo do Rio Paraguaçu situada em região semiárida na Região Hidrográfica do Atlântico Leste, Bacia do Paraguaçu, na Bahia. A barragem foi construída na década de 80 com a função de abastecer os municípios circunvizinhos. Para preservação da região foi criada em 1999 a Área de Proteção Ambiental (APA) do Lago de Pedra do Cavalo, com 30.156 ha, formada pelos municípios de Conceição de Feira, Feira de Santana, São Gonçalo dos Campos, Cachoeira, Antônio Cardoso, Santo Estevão, Governador Mangabeira, Castro Alves, Cruz das Almas, Muritiba e São Félix (BAHIA, 1997). Desses, apenas os 3 primeiros, além de Tanquinho, Santa Bárbara e Santanópolis são atendidos pelo SIAA-FSA.

Os municípios atendidos pelo Sistema, todos localizados no semiárido baiano, somam mais de 700 mil habitantes, sendo $95,5 \%$ da população registrada como abastecida, tendo Feira de Santana, com quase 600 mil habitantes, seu principal centro consumidor (BRASIL/SNS, 2019).

A prestadora de serviço responsável pelo atendimento ao SIAA-FSA é a Empresa Baiana de Águas e Saneamento S.A (Embasa). Apesar do elevado índice de abastecimento, somam-se a população da APA não atendida pelo serviço (251 mil pessoas) os outros 31.937 habitantes do SIAA que não recebem água tratada em suas residências.

A partir dessas informações, diante da evolução demográfica projetada para os municípios, o presente trabalho tem por objetivo analisar a capacidade de suprimento da demanda de água no Sistema Integrado de Abastecimento de Água de Feira de Santana (SIAA-FSA) em cenários alternativos modificadores da demanda (consumo per capita) e oferta (redução de perdas). 


\section{METODOLOGIA}

Segundo estimativas da Superintendência de Estudos Econômicos e Sociais da Bahia (SEI-BA) os municípios do SIAA-FSA terão expansão populacional de aproximadamente $11,92 \%$ entre 2020 e 2030. Essa variação será acompanhada por pressão de demanda sobre diversos serviços e produtos, entre os quais aqueles relacionados ao saneamento.

Centrando as atenções no abastecimento de água, em consonância com o objetivo do presente trabalho, essa pressão de demanda deve observar o perfil de consumo dos habitantes e a estrutura operacional dos prestadores para atendimento, considerando que o volume de água produzida é limitado pela infraestrutura disponível para tratamento e distribuição e pela outorga de direito de uso concedida pelo órgão gestor.

Dessa forma, foram coletadas informações dos municípios pertencentes ao SIAA-FSA junto ao banco de dados desagregados do SNIS, cujos dados mais atuais tem 2018 como ano base (BRASIL/SNS, 2019). O SNIS agrega um conjunto de informações e indicadores sobre serviços de abastecimento de água, esgotamento sanitário e resíduos sólidos. Os dados são fornecidos anualmente pelos prestadores, sendo o Diagnóstico de Água e Esgotos (DA\&E) um conjunto de informações de caráter operacional, gerencial, financeiro e de qualidade sobre a prestação de serviços de água e esgoto. Os dados brutos utilizados na simulação, caracterizam o SIAA-FSA a partir de variáveis selecionadas relacionadas a aspectos populacionais e de estrutura de atendimento (Quadro 1).

Quadro 1: Informações de Água Selecionadas para Caracterização dos Sistemas de Abastecimento. Fonte: Brasil/SNS (2019)

\begin{tabular}{|c|c|c|}
\hline Variável & Descrição & Unidade \\
\hline AG001 & $\begin{array}{l}\text { População total atendida com abastecimento de água. Representa } \\
\text { a população do município têm acesso ao serviço }\end{array}$ & Habitantes \\
\hline AG002 & $\begin{array}{l}\text { Quantidade de ligações ativas de água que são as extremidades } \\
\text { das unidades consumidoras com a rede pública, providas ou não } \\
\text { de hidrômetro. Podem se desdobram em várias economias. }\end{array}$ & Ligações \\
\hline AG003 & $\begin{array}{l}\text { Quantidade de economias ativas de água que representam a } \\
\text { canalização da água dentro do alimentador predial. Cada } \\
\text { economia pode ser compreendida como unidade domiciliar }\end{array}$ & Economias \\
\hline AG006 & $\begin{array}{l}\text { Volume de água produzido. Representa o volume de água } \\
\text { disponibilizado para distribuição ou exportação para outro } \\
\text { sistema, após tratamento em ETA. }\end{array}$ & $\begin{array}{c}1.000 \\
\mathrm{~m}^{3} / \mathrm{ano}\end{array}$ \\
\hline AG010 & $\begin{array}{l}\text { Volume de água consumido. Representa os valores consumidos } \\
\text { por todos os usuários (medidos ou estimados) somados ao } \\
\text { volume de água tratada exportada para outros sistemas }\end{array}$ & $\begin{array}{c}1.000 \\
\mathrm{~m}^{3} / \mathrm{ano}\end{array}$ \\
\hline AG024 & $\begin{array}{l}\text { Volume de água de serviço, utilizado em atividades operacionais } \\
\text { e especiais, acrescido do volume de água recuperado. }\end{array}$ & $\begin{array}{c}1.000 \\
\mathrm{~m}^{3} / \mathrm{ano}\end{array}$ \\
\hline
\end{tabular}

As informações selecionadas foram agregadas para totalização dos dados do SIAAFSA, tornando possível recalcular indicadores específicos do serviço de abastecimento. Utilizando a metodologia do DA\&E, caracterizou-se o comportamento do consumidor final (habitantes dos municípios atendidos pelo Sistema) quanto ao uso da água fornecida, bem como do prestador (Embasa) quanto a eficiência no processo de distribuição (Quadro 2).

Persp. Online: hum \& sociais aplicada., Campos dos Goytacazes, 29 (10)34-45- 2020 seer.perspectivasonline.com.br 
Quadro 2: Indicadores Operacionais Selecionados para Caracterização de Usuários Finais e Prestador do Serviço de Abastecimento. Fonte: Brasil/SNS (2019)

\begin{tabular}{|c|l|c|}
\hline Código & \multicolumn{1}{|c|}{ Descrição } & Unidade \\
\hline IN022 & $\begin{array}{l}\text { Consumo médio per capita de água que expressa a } \\
\text { relação entre volume de água disponibilizado e a } \\
\text { população atendida com abastecimento de água. }\end{array}$ & $\begin{array}{c}\text { 1/habitante/ } \\
\text { dia }\end{array}$ \\
\hline IN049 & $\begin{array}{l}\text { Índice de perdas na distribuição que compreende a } \\
\text { porcentagem de água produzida perdida em relação ao } \\
\text { volume disponibilizado, durante o serviço de distribuição }\end{array}$ & $\%$ \\
\hline IN051 & $\begin{array}{l}\text { Índice de perdas por ligação que indica a proporção das } \\
\text { perdas do volume de água distribuído, considerando o } \\
\text { número de ligações ativas. }\end{array}$ & $\begin{array}{c}\text { litros/ligação } \\
\text { /dia }\end{array}$ \\
\hline IN052 & $\begin{array}{l}\text { Índice de consumo de água que indica quanto da água } \\
\text { produzida é efetivamente consumida de forma direta } \\
\text { (consumidores finais) ou indireta (água de serviço ou } \\
\text { exportada) }\end{array}$ & $\%$ \\
\hline
\end{tabular}

Para construção das previsões de demanda de água decorrente de variações populacionais municipais foram utilizados os Indicadores Demográficos projetados disponibilizados pela SEI-BA para os anos de 2020, 2025 e 2030 (SEI, 2013). Assim, foram construídos cenários que simulam a demanda e disponibilidade de água para abastecimento público no Sistema, diante de manutenção e alteração em variáveis relacionadas ao comportamento de consumo da população atendida.

No Cenário 1 foram feitas a projeções de demanda considerando manutenção das atuais médias de consumo per capita da população (Equação 1). Nesse Cenário observa-se a existência de saldo positivo ou negativo ao longo dos anos caso não sejam adotadas medidas ou utilizado instrumentos que modifiquem o padrão médio de consumo da população.

$$
\text { Demanda }=\frac{(\text { Pop.Total } \times \% \text { Atendimento } \times \text { IN022) } \times 365}{1.000 .000}
$$

O Cenário 2 busca refletir as variações na demanda considerando que a mudança no quantitativo demográfico será acompanhada por mudanças também no consumo médio da população, atingindo o nível 110 1/hab./dia. Esse volume, segundo a Organização Mundial de Saúde (OMS) é indicado como o limite mínimo para que um sistema seja considerado adequado na oferta de água, tornando possível, de forma satisfatória, a higiene pessoal, do ambiente e vestuário, a cocção de alimentos e o consumo direto (WHO, 2003). Este Cenário altera então o índice IN022 utilizado na equação 1.

Na projeção das disponibilidades que envolvem variações na oferta de água, foram feitas alterações das atuais médias de perdas na distribuição pelo prestador do serviço. Relevante observar que embora definido como perdas "na distribuição", o IN049 abrange perdas reais decorrentes de vazamentos e perdas aparentes, resultantes de não faturamento por falhas em hidrômetros ou consumo não autorizado (BEZERRA; PERTEL; MACEDO, 2019). Contudo, conforme apontado por Tardelli Filho (2016), estudos realizados em grandes cidade de diversos países, incluindo São Paulo e Buenos Aires na América do Sul, comprovam que as perdas reais são geralmente mais significativas que as aparentes, evidenciando o efetivo

Persp. Online: hum \& sociais aplicada., Campos dos Goytacazes, 29 (10)34-45- 2020 seer.perspectivasonline.com.br 
desperdício do recurso hídrico. No presente trabalho, diante da indisponibilidade de informações que permitam o adequado rateio entre as perdas reais e aparentes, assume-se que também no SIAA-FSA estas são menos expressivas que aquelas, adotando-se como hipótese a não existência de perdas aparentes. Assim, o IN049 torna-se exclusivamente fundamentado em perdas reais do sistema.

Dessa forma, para análise das disponibilidades hídricas foram consideradas variações na oferta decorrentes de manutenção (H0 - Equação 2) ou redução das perdas reais que impactariam o IN049 em 50\% (H1 - Equação 3) e 25\% (H2 - Equação 4). As disponibilidades são então calculadas conforme equações apresentadas no Quadro 3.

Quadro 3: Equações de Cálculo da Disponibilidade Hídrica em Hipóteses de Variação nas

Perdas na Distribuição

\begin{tabular}{|c|cc|}
\hline Hipótese & Equação \\
\hline $\begin{array}{c}\text { Ho: Manutenção } \\
\text { do índice de perdas }\end{array}$ & $H_{0}=A G 006 \times(1-I N 049-A G 024)-$ Demanda & $(2)$ \\
\hline $\begin{array}{c}\text { H1: Redução das } \\
\text { perdas em 50\% }\end{array}$ & $H_{1}=A G 006 \times(1-(I N 049 \times 0,5)-A G 024)-$ Demanda \\
\hline $\begin{array}{c}\text { H2: Redução das } \\
\text { perdas em 25\% }\end{array}$ & $H_{2}=A G 006 \times(1-(I N 049 \times 0,75)-A G 024)-$ Demanda \\
\hline
\end{tabular}

As três hipóteses relacionadas ao índice de perdas na distribuição, representado pelo IN049, foram simuladas nos dois Cenários de demanda.

\section{RESULTADOS E DISCUSSÃO}

Os indicadores permitiram identificar semelhança nos índices que caracterizam o serviço de abastecimento de água entre os municípios que integram o SIAA-FSA. Os Municípios do Sistema revelam-se como cidades horizontais no que diz respeito ao sistema de saneamento básico, pois possuem quantidades próximas de economias e ligações.

O consumo per capita de água dos habitantes atendidos pelo Sistema oscila entre 81,12 Nhab.dia (Conceição da Feira) e 99,82 1/hab.dia (Santanópolis), atingindo uma média inferior ao indicado pela OMS. Relevante considerar que essa média pode ser resultado da indisponibilidade hídrica conjuntural característica do semiárido, associada a vazamentos que reduzem a oferta (Figura 2). 


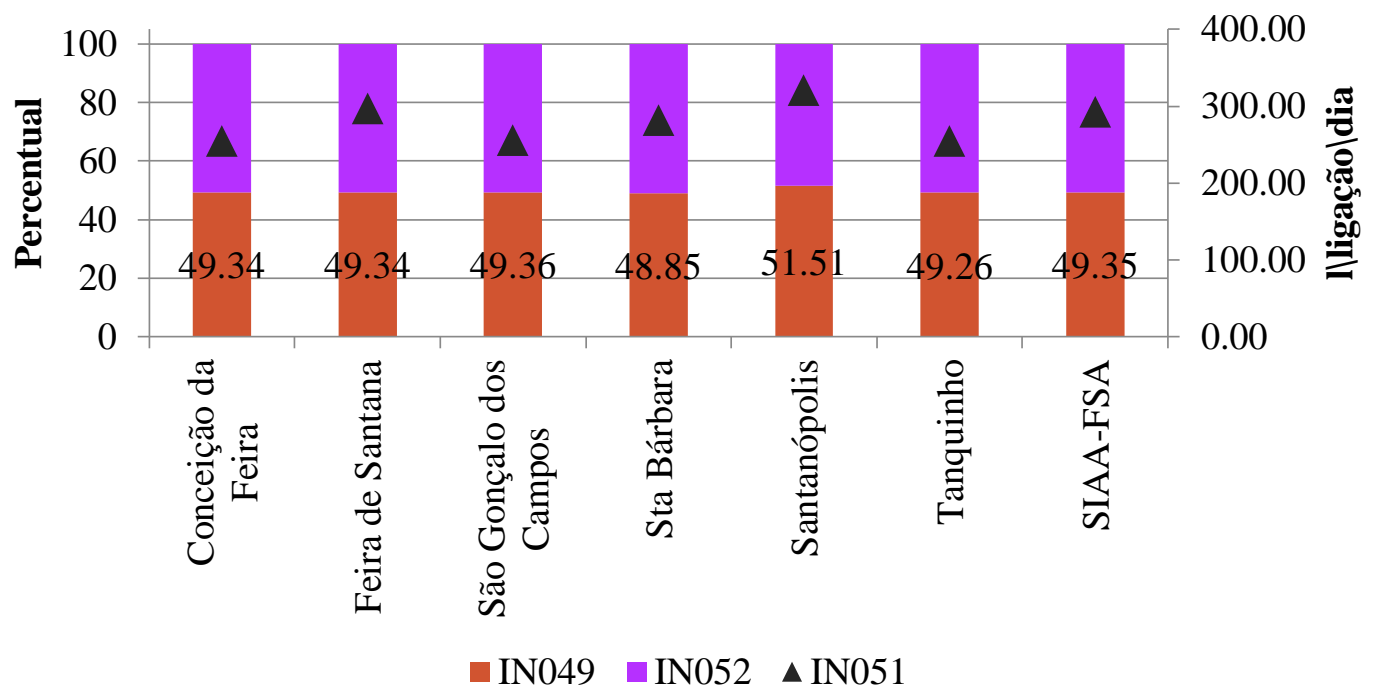

Figura 2: Indicadores de perdas e consumo de água dos municípios do SIAA-FSA. (Fonte: SNIS, 2019).

O SIAA-FSA produz anualmente 43.282,11 mil $\mathrm{m}^{3}$ de água atendendo a uma população que consome uma média de 86,80 1/hab./dia. Os dados indicam que a soma dos volumes disponibilizados para consumo e utilizados em serviços no próprio sistema comprometem $50,41 \%$ do total produzido. O saldo restante, subtraído o volume importado por Santa Bárbara (21,8 $\left.\mathrm{m}^{3} / \mathrm{ano}\right)$, resulta em 21.462,73 $\mathrm{mil} \mathrm{m}^{3}$ anuais contabilizados como perdas de distribuição, equivalente a uma redução de 49,59\% do volume produzido (Figura 3). Tal característica predomina em todos os municípios do Sistema.

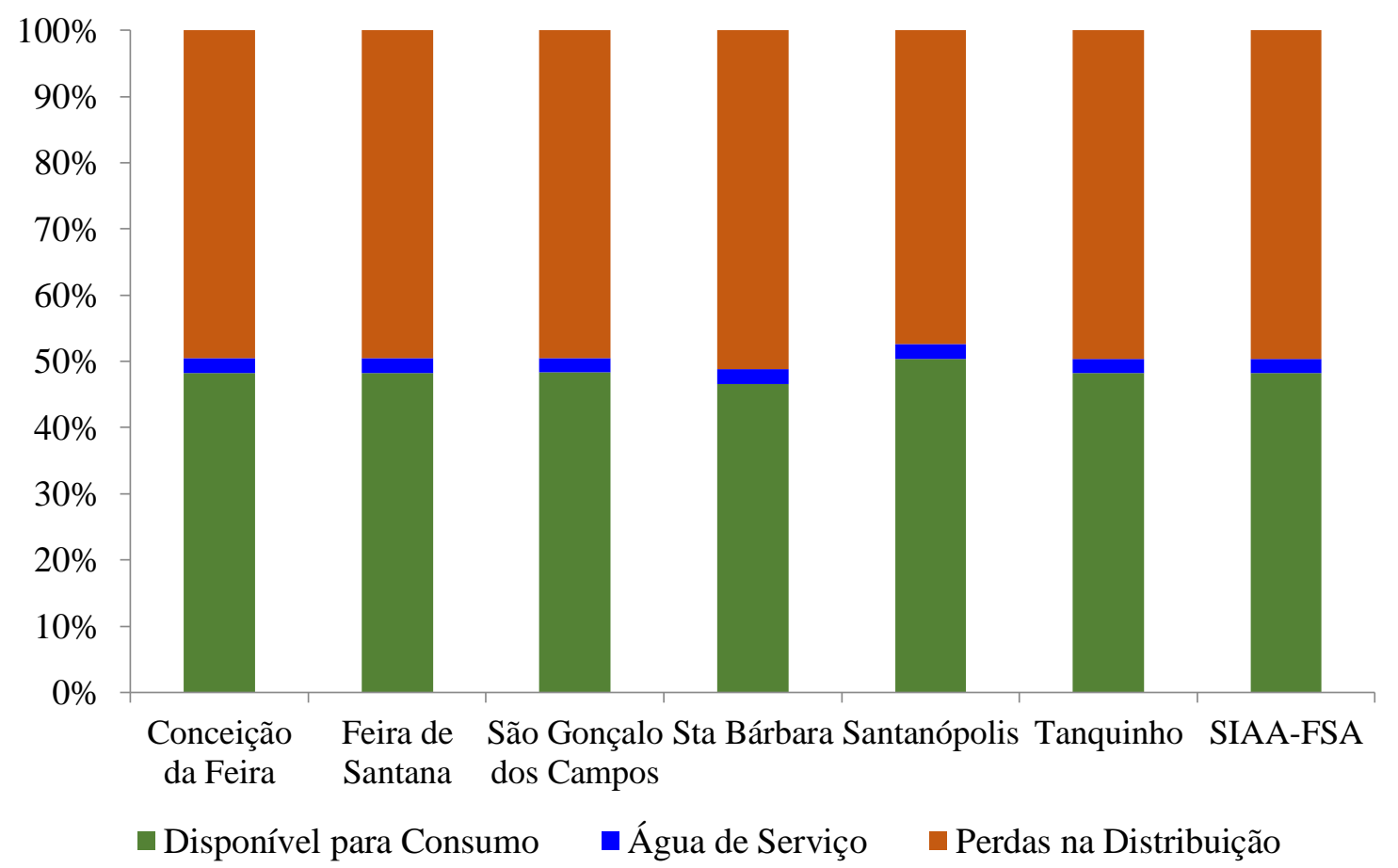

Figura 3: Repartição percentual do volume de água produzida no SIAA-FSA segundo categorias de uso e perdas. (Fonte: Elaborado a partir de dados do SNIS, 2019).

Persp. Online: hum \& sociais aplicada., Campos dos Goytacazes, 29 (10)34-45- 2020 seer.perspectivasonline.com.br 
Na simulação das projeções populacionais, no Cenário 01 evidencia-se que mantendose os indicadores apresentados (H0), a demanda em 2018 já se mostrava superior a disponibilidade real (Tabela 1). Isto implica em um não atendimento diário a toda população dos municípios, do que resulta em armazenamento (caixas d'água) para garantir as intermitências no fornecimento que pressionam o consumo para níveis mais baixos. Explicam-se assim as 2.234 interrupções sistemáticas registradas que totalizaram 516.205 horas no ano de 2018.

Tabela 1: Cenário 01: Manutenção das médias de consumo

\begin{tabular}{c|c|c|c|c|c}
\hline \multirow{2}{*}{ Ano } & $\begin{array}{c}\text { População } \\
\text { Total }\end{array}$ & Demanda & \multicolumn{3}{|c}{ Disponibilidade em 1.000 mªno } \\
\cline { 2 - 6 } & Habitantes & $\mathbf{1 . 0 0 0 ~ m}$ 3 /ano & H0 & H1 & H2 \\
\hline 2018 & 706.967 & $21.386,06$ & $-470,86$ & $10.208,54$ & $4.868,84$ \\
2020 & 749.461 & $22.671,52$ & $-1.756,32$ & $8.923,08$ & $3.583,38$ \\
2025 & 794.256 & $24.026,59$ & $-3.111,39$ & $7.568,01$ & $2.228,31$ \\
2030 & 838.814 & $25.374,49$ & $-4.459,29$ & $6.220,11$ & 880,41 \\
\hline
\end{tabular}

Ainda neste Cenário 01 de não alteração dos padrões de consumo, verifica-se que investimentos que resultem em maior eficiência na distribuição (correção de vazamentos) e consequente redução dos índices de perdas (IN049) podem garantir a adequada disponibilidade de água para o período projetado, mesmo quando a redução signifique apenas $25 \%$ dos índices atuais (H2). Contudo, os benefícios da maior racionalidade podem ser ainda mais significativos com a redução do IN049 em 50\% (H1), uma solução mais sustentável que pode ainda resultar em externalidades positivas que venham a beneficiar o meio ambiente e sociedade. A redução na captação disponibiliza água para outros usos, inclusive o ambiental, reduzindo também os custos extras dos desperdícios que são pagos pela tarifas cobradas à população.

$\mathrm{Na}$ sequência das simulações, observou-se as hipóteses estabelecidas diante do Cenário 02 que altera o consumo diário per capita da população para o nível mínimo de adequação estabelecido pela OMS (110 litros/habitante), sendo esse volume abaixo da média nacional $(154,9$ litros) embora próximo a média do nordeste $(115,4$ litros) e da Bahia $(115,6)$ (BRASIL/SNS, 2019).

As simulações do Cenário 02 resultam numa demanda do Sistema equivalente a mais de $70,0 \%$ do volume produzido em 2025, exigindo elevados investimentos para melhoria da eficiência do sistema de distribuição e redução do uso perdulário (Tabela 2). Os resultados corroboram a insuficiência da água ofertada, não apenas no atual nível de IN049 (H0), mas também em face de investimentos insuficientes para redução dos vazamentos $(\mathrm{H} 2)$.

Persp. Online: hum \& sociais aplicada., Campos dos Goytacazes, 29 (10)34-45- 2020 seer.perspectivasonline.com.br 
Tabela 2: Cenário 02: Alteração da média de consumo

\begin{tabular}{|c|c|c|c|c|c|}
\hline \multirow{2}{*}{ Ano } & \multirow{2}{*}{$\begin{array}{l}\text { População } \\
\text { Habitantes }\end{array}$} & \multirow{2}{*}{$\begin{array}{c}\text { Demanda } \\
1.000 \mathrm{~m}^{3} / \text { ano }\end{array}$} & \multicolumn{3}{|c|}{ Disponibilidade $1.000 \mathrm{~m}^{3} / \mathrm{ano}$} \\
\hline & & & H0 & H1 & H2 \\
\hline 2018 & 706.967 & $27.102,45$ & $-470,86$ & $4.492,15$ & $-847,55$ \\
\hline 2020 & 749.461 & $28.731,51$ & $-7.816,31$ & $2.863,09$ & $-2.476,61$ \\
\hline 2025 & 794.256 & $30.448,79$ & $-9.533,58$ & $1.145,82$ & $-4.193,88$ \\
\hline 2030 & 838.814 & $32.156,97$ & $-11.241,77$ & $-562,37$ & $-5.902,07$ \\
\hline
\end{tabular}

Embora investimentos que resultem em redução de 50\% do IN049 possam garantir a oferta de água a níveis mais elevados até os próximos 5 anos (2025), tal hipótese não se apresenta como sustentável em um prazo mais longo (2030).

Para avaliação dos resultados faz-se necessário considerar que a Embasa realiza um serviço que lhe permite prioridade na concessão de direito de uso para captação de água. Todavia, a ineficiência do sistema de distribuição caraterizada pelos elevados índices de perdas, cria obstáculos a defesa da manutenção dessa prioridade, posto que não apenas implica em custos operacionais excessivos cujo ônus é repassado aos consumidores finais, mas também em possível agravamento do estresse hídrico. Tal constatação torna-se ainda mais pertinente quando observado que o Sistema Integrado de Feira de Santana localiza-se em pleno semiárido, onde a escassez de água se apresenta como característica descritiva da região.

As simulações evidenciam que para manutenção dos atuais níveis de abastecimento, já quantitativamente estabelecidos como insatisfatórios, as pressões sobre os consumidores finais são insuficientes, mesmo diante da ocorrência de aumento de tarifa. A baixa elasticidade preço da demanda por água (WHITTINGTON, D.; HANEMANN, W. M, 2006) revela que a mesma sofre impactos menos que proporcionais aos aumentos de preços. Dessa forma, não apenas deve ser atribuído ao prestador de serviço a responsabilidade pelas perdas, mas também faz-se mister indicar ao mesmo a necessidade de efetivas ações mitigadoras que reduzam o uso perdulário (TARDELLI FILHO, 2015).

A crise hídrica que atingiu vários estados brasileiros evidenciam a necessidade de mudança no comportamento dos prestadores redefinindo estratégias, procedimentos e comportamentos em um contexto hídrico ambiental mais restrito.

\section{CONCLUSÕES}

A existência do serviço de abastecimento além de garantir o acesso à água que é um recurso indispensável para sobrevivência humana gera externalidades positivas de cunho social, político e econômico. Seus serviços garantem uma melhor qualidade de vida para população, com significativos impactos na saúde, educação e produtividade.

A meta de universalização dos serviços de abastecimento de água e esgotamento sanitário busca não apenas a garantia de um direito constitucional já estabelecido, mas também a consolidação de bases fundamentais para o desenvolvimento econômico do país. Contudo, o atendimento dessa meta enfrenta obstáculos diversos de âmbito normativo

Persp. Online: hum \& sociais aplicada., Campos dos Goytacazes, 29 (10)34-45- 2020 seer.perspectivasonline.com.br 
(ausência de planos municipais de saneamento), financeiro (alto volume de recursos para investimentos), operacionais (elevados índices de perdas dos prestadores), sociais (comportamento perdulário dos usuários) e ambientais (escassez do recurso hídrico).

Delimitando a análise ao serviço de abastecimento de água, o cenário de crise hídrica é agravado pelo crescimento populacional, elevando a demanda em um contexto de oferta já insuficiente. Centrando nesse aspecto, o presente trabalho evidenciou a restrição na oferta decorrente do uso perdulário da Embasa, prestadora de serviços de abastecimento de água no Sistema Integrado Feira de Santana (SIAA - FSA), onde quase metade do volume produzido é perdido na rede de distribuição.

Diante de projeções demográficas, mantido os atuais índices de perdas e consumo, o sistema já resulta em insuficiência que acarreta em interrupções no fornecimento, tornando as caixas d'água uma necessidade. A situação agrava-se diante de um possível aumento no consumo per capita aos níveis adequados, conforme indicados pela OMS, demandando investimentos vultosos na melhoria da eficiência do sistema, não sendo ainda assim uma solução sustentável no longo prazo.

Conclui-se que diante das projeções de expansão demográfica e consequente variação na demanda de água, o SIAA-FSA requer medidas imediatas e amplas que envolvem sérias mudanças estruturais e operacionais na prestação do serviço de abastecimento. Concomitantemente, deve ser observado que a ampliação da oferta enfrenta obstáculos relacionados a disponibilidade hídrica, característica crítica do semiárido, bem como a necessária multiplicidade de usos, visto que apesar de prioritário, o abastecimento não pode ser uso exclusivo do recurso.

A universalização dos serviços de saneamento, como meta para alcance do desenvolvimento sustentável, passa pela preocupação com estudos locais e com a rede de distribuição existente para projetação mais concisa, adequada e eficiente. Contudo, deve ser permanentemente pautado que o recurso hídrico é um bem de elevado valor social, político e econômico, exigindo atenção interdisciplinar.

\section{REFERÊNCIAS}

BAHIA (Estado). Decreto $n^{\circ}$ 6.548, de 18 de julho de 1997. Cria a Área de Proteção Ambiental - APA do Lago de Pedra do Cavalo, nos Municípios de Conceição de Feira, Cachoeira, Antônio Cardoso, Santo Estevão, Governador Mangabeira, Castro Alves, Cruz das Almas, Feira de Santana, Muritiba, São Félix e São Gonçalo dos Campos, e dá outras providências. Diário Oficial do Estado da Bahia. Salvador, BA, 20 jul. 1997.

BARRAQUÉ, B. Les trois genies de l'eau urbaine. In: BARRAQUÉ, B.; ROCHE, P.-A. (org.). Peurs et plaisirs de l'eau. Paris: Hermann, 2010.

BEZERRA, Saulo de Tarso Marques; PERTEL, Monica; MACEDO, José Eloim Silva de. Avaliação de desempenho dos sistemas de abastecimento de água do Agreste brasileiro. Ambiente Construído. Porto Alegre, v. 19, n. 3, p. 249-258, Set. 2019. https://doi.org/10.1590/s1678-86212019000300336.

BRASIL, MINISTÉRIO DO DESENVOLVIMENTO REGIONAL; SECRETARIA NACIONAL DE SANEAMENTO (BRASIL/SNS). Sistema Nacional de Informações de

Persp. Online: hum \& sociais aplicada., Campos dos Goytacazes, 29 (10)34-45- 2020 seer.perspectivasonline.com.br 
Saneamento - 24${ }^{\circ}$. Diagnóstico dos Serviços de Água e Esgoto 2018. Brasília: SNS/MDR, 2019, 180p.

BRASIL. Lei $\mathbf{n}^{\mathbf{0}}$ 11.445, de 05 de janeiro de 2005. Estabelece diretrizes nacionais para o saneamento básico; altera as Leis nos 6.766, de 19 de dezembro de 1979, 8.036, de 11 de maio de 1990, 8.666, de 21 de junho de 1993, 8.987, de 13 de fevereiro de. Lei Saneamento. Brasília, Disponível em: http://www.planalto.gov.br/ccivil_03/_ato2007-010/2007/lei/ 111445.htm. Acesso em: 08 maio 2016.

FUNDAÇÃO NACIONAL DE SAÚDE (FUNASA). Impactos na Saúde e no Sistema Único de Saúde Decorrentes de Agravos Relacionados a um Saneamento Ambiental Inadequado. Brasília: Assessoria de Comunicação e Educação em Saúde, 2010.

LAMBERT, A.; HIRNER, W. Losses from Water Supply Systems: Standard Terminology and Recommended Performance Measures. International Water Association. The Blue Pages. London: IWA, 2000.

MACHADO, A. M. O. B. S. M.; VALE, M. S. Desenvolvimento Sustentável: ponto e contraponto das economias ambiental neoclássica e ecológica nos processos de tomada de decisão. Humanas \& Sociais Aplicadas, v. 5, n. 14,15 dez. 2015. https://doi.org/10.25242/88765142015839.

PAVAN DE SOUZA, F. ; PEREIRA SANTOS, A. S.; TEIXEIRA, T.; PERTEL, M.; V. ACSERALD, M.; MARCONDES, Q.; HILDEBRANDT, D. Aplicação do Método de Valoração Contingente para Mensurar a Percepção Sócio Ambiental dos Moradores que Vivem no Entorno da Lagoa do Vigário. Humanas \& Sociais Aplicadas, v. 6, n. 15, 28 jun. 2016. https://doi.org/10.25242/88766152016971.

SIQUEIRA, T. A.; ARAÚJO, R. DE S. Programas de Habitação Social no Brasil. Humanas \& Sociais Aplicadas, v. 4, n. 10, 11 dez. 2014. https://doi.org/10.25242/88764102014540.

SISTEMA NACIONAL DE INFORMAÇÕES DE SANEAMENTO (SNIS). Água e Esgotos - Série Histórica. Base de Dados. 2019. Disponível em: 〈http://app4.cidades.gov.br/serieHistorica/>. Acesso em 12dez19.

SUPERINTENDÊNCIA DE ESTUDOS ECONÔMICOS E SOCIAIS DA BAHIA (SEI). Projeções Populacionais para Bahia 2010 - 2030. Salvador, 2013.

TARDElli FILHO, J. Controle e Redução de Perdas nos Sistemas Públicos de Abastecimento de Água. Posicionamentos e contribuições técnicas da ABES. Rio de Janeiro, 2015. Internet. Disponível em: http://abes-dn.org.br/pdf/28Cbesa/Perdas_Abes.pdf.

TARDELLI FILHO, J. Aspectos relevantes do controle de perdas em sistemas públicos de abastecimento de água. Revista DAE. São Paulo: SABESP, jan-abr 2016.

WHITTINGTON, D.; HANEMANN, W. M. The economic costs and benefits of investments in municipal water and sanitation infrastructure: a global perspective. Workingpaper $n^{\circ} 1027$. University of California at Berkeley, Department of Agricultural and Resource Economics and Policy, 2006.

WORLD HEALTH ORGANIZATION (WHO). Right to Water. Health and human rights publication séries, no. 3. WHO: Genebra (Suiça), 2003.

Persp. Online: hum \& sociais aplicada., Campos dos Goytacazes, 29 (10)34-45- 2020 seer.perspectivasonline.com.br 